\title{
EVALUATION OF THE RELATIVE VALIDITY OF FOOD RECORD CHARTS (FRCS) USED WITHIN THE HOSPITAL SETTING TO ESTIMATE ENERGY AND PROTEIN INTAKES
}

\author{
L. Bartkowiak, J. Jones, E. Bannerman
}

\begin{abstract}
Objective: To determine the relative validity of two semi-quantitative food record charts (FRCs) to estimate patients' energy and protein intakes. Design, setting $\mathcal{E}$ participants: A pilot service evaluation of twenty seven patients in adult acute care wards in an NHS hospital, Scotland UK. Measurements: Weighed plate-wastage was undertaken to measure dietary intakes of patients being monitored using FRCs on two adult acute wards. Both FRCs listed food items typically served at each meal alongwith an indication of portion size on a Likert scale. All items consumed over 12 hours (three meals and two snacks) were weighed prior to provision and all left-over items were weighed once eating had terminated to determine amounts consumed. Estimated energy and protein intakes from both methods were determined and compared using 95\% limits of agreement. Results: FRCs on both wards underestimated energy and protein intakes (mean bias (95\% CI): Ward A, n=12; -219 (-1170, 732) kcal; -five (-50, 40) gram and Ward B, $n=15 ;-437(-1403,529)$ kcal, $-18(-57,21)$ gram). All 12 FRCs on ward A and 13 out of 15 records on ward B were incomplete due to omissions of whole meals or omissions of particular foods and drinks throughout the day. Details of 'portion eaten' were frequently omitted from the completed FRCs on both wards. Discrepancies existed between food items documented on FRCs to those observed and weighed. Conclusions: Further development of FRCs and training of staff is needed to ensure appropriate completion and thus accurate estimation of patients' intakes to better inform nutritional care.
\end{abstract}

Key words: Dietary assessment, food record charts, clinical nutrition.

\section{Introduction}

Studies suggest that inadequate food and fluid consumption exists in hospitals (1-3) and that poor intakes are an independent risk factor for poor clinical outcome $(2,4)$. In spite of standards throughout Europe, stating the necessity of monitoring food intakes particularly for those highlighted to be at nutritional risk (5-7), studies suggest that poor intakes remain largely undetected and thus are likely to be poorly managed $(2,7-9)$. This highlights the importance of monitoring patient intakes in conjunction with nutritional screening (7), with both being treated as integral parts of nutrition and dietetic care processes $(10,11)$.

Food Record Charts (FRCs) are often developed at a local level and thus uniformity across and within hospitals may be lacking. Some charts consist of structured checklists with guides to aid completion

School of Health Sciences, Queen Margaret University, Queen Margaret University Drive, Musselburgh, East Lothian, Scotland, United Kingdom. EH21 $6 \mathrm{UU}$

Corresponding Author: Jacklyn Jones, School of Health Sciences, Queen Margaret University, Queen Margaret University Drive, Musselburgh, East Lothian, Scotland, United Kingdom EH21 6UU, JJones@qmu.ac.uk

(12-14), whilst others are unstructured open-ended diaries (15-17), thus lack standardisation. It has been recommended that studies are undertaken to validate simple dietary assessment records (7). 'Guesstimates' by different nursing and clinical support staff (CSS) are often relied upon to determine individual nutritional intakes, and this has been deemed to be inadequate (18), thus raising concerns as to the usefulness of documented information. Priority given to other nursing duties, time constraints, poor understanding of the importance of accurate completion of FRCs and a belief that professional subjective judgement is just as good, may be factors that prevent successful completion, as has been reported for nutritional screening tools (19). This study aimed to evaluate the relative validity of two different FRCs used within a clinical setting to determine an accurate assessment of dietary intakes of inpatients.

\section{Methods}

A pilot service evaluation was undertaken to determine the relative validity of two different FRCs used within two adult acute care wards, in a general National Health Service (NHS) hospital in Scotland, UK. 
A plated-food service system operated within the hospital which supplied all patient meals. Hot and cold drinks (including tea, coffee and milk) were offered with and between meals (the latter with snacks).

The FRCs listed generic food items typically served on the ward at each meal (for example: meat, fish, vegetarian, pasta, potato; these lists differing between the two wards). Likert scales allowed for detailing 'portion eaten' as either a five point (WARD A: 'Eaten 0, 1/4, 1/2, 3/4, All') or a three point (WARD B: 'Eaten 0, 1/2, All') scale. Food items and amounts eaten were circled on the FRC corresponding to patients' intakes by nursing or CSS staff. Data was gathered over a two week period, with three to five FRCs and corresponding plate-waste feasibly evaluated each day. Anonymised copies of the FRCs were printed with unique subject numbers, to link these with corresponding plate-wastage.

Plate-wastage methodology (20-22) was completed by the researcher (LB) at the same time as corresponding FRCs over a 12 hour period $(0700-1900 \mathrm{hrs})$. This timeframe included provision of all meals (breakfast, lunch and evening meals), in-between meal drinks and snacks (mid-morning and mid-afternoon) and one milk round each day. Individual components for each meal were weighed (1 gram) using calibrated digital scales using duplicate plated meals. Portion sizes were standardised through use of standard serving utensils throughout the food service and also training on portion control for catering staff.

Once eating had terminated, any leftover foods were weighed separately for individual components and these then subtracted from the weight of the meal provided in order to determine the amount of food consumed (22). All snacks provided on the ward had a standard portion size. Any left-overs were deducted from what was provided to determine intakes (as detailed above).

Standard drinking vessels were used on the ward, therefore one-off baseline measurements were made to allow intakes to be determined.
The provision of all meals, drinks and snacks within the stated 12 hour period was observed by the researcher (LB), to allow for the documentation of any foodstuffs which were consumed or changed and which may not have been identified through weighing plate-wastage alone, for example, added sugar and milk.

The standard weights obtained for foods prior to consumption along with firstly individual plate-wastage for each food item (plate wastage methodology) and secondly 'portion eaten' values ('0, 1/4, 1/2,3/4, All' ward A; '0, 1/2, All' ward B) detailed on the FRCs were used to determine amounts consumed by the FRC and reference method. Energy and protein intakes from both methods were determined using Nutmeg N4P dietary analysis software (Nutmeg UK Ltd Nutritional Analysis Software for Web Version 1). These estimates were based solely on the information recorded by their respective methodology and only reflected the 12 hour study period.

The project was deemed a service evaluation by the South East Scotland Research Ethics Committee.

Relative validity of the FRCs was determined using Bland-Altman analysis (23). Spearman's correlation was used to examine any associations between estimates determined between the two methodologies (statistical significance $p<0.05)$. Subjective comparison of the information documented on the FRCs was compared to the information documented by the researcher (LB) for plate-wastage methodology to identify any specific inconsistencies, inaccuracies or omissions.

\section{Results}

Food record charts (FRCs) and corresponding weighed plate-wastage data were collected for 27 patients (WARD A $n=12$ : WARD B $n=15)$. FRCs used on both wards underestimated energy intakes (WARD A -219kcal; WARD B -437 kcal) (figure 1) and protein intakes (WARD A -5g; WARD B -18g) compared to those estimated using weighed plate-wastage (Table 1).

Table 1

Energy (kcal) and protein $(\mathrm{g})$ intakes estimated from FRCs and corresponding weighed plate-wastage over a 12 hour period $(7 \mathrm{am}-7 \mathrm{pm})$ in two adult acute wards $(\mathrm{n}=27)$

\begin{tabular}{|c|c|c|c|c|c|}
\hline \multicolumn{3}{|c|}{ Mean (SD) } & \multirow[t]{2}{*}{${ }^{*}$ Bias } & \multirow[t]{2}{*}{ SD } & \multirow[t]{2}{*}{ +95\% Limits of Agreement } \\
\hline & Weighed Plate-Wastage & FRCs & & & \\
\hline \multicolumn{6}{|l|}{ Ward A, n=12 } \\
\hline Energy (kcal) & $959(532)$ & $740(493)$ & -219 & 485 & $-1170,732$ \\
\hline Protein $(g)$ & $37(24)$ & $31(23)$ & -5 & 23 & $-50,40$ \\
\hline \multicolumn{6}{|l|}{ Ward $B, n=15$} \\
\hline Energy (kcal) & $813(505)$ & $376(317)$ & -437 & 493 & $-1403,529$ \\
\hline Protein (g) & $33(19)$ & $15(14)$ & -18 & 20 & $-57,21$ \\
\hline
\end{tabular}

${ }^{*}$ Bias $=$ mean differences $($ FRC - weighed intake $)$; +Limits of Agreement $=$ bias $\pm 1.96 \mathrm{SD}$ 
The difference in energy estimated from FRCs and the corresponding plate-wastage was significantly correlated with energy intakes estimated from plate-wastage for both wards (Ward A: $\mathrm{r}=-0.615, \mathrm{p}<0.05$ and Ward B: $\mathrm{r}=$ $-0.807, \mathrm{p}<0.05$ ) (Figure $2 \mathrm{a} \& 2 \mathrm{~b}$ ). Similarly, a significant negative correlation was seen between the difference in protein intakes estimated from FRCs and plate-wastage and estimates of protein intakes from plate-wastage for Ward B $(\mathrm{r}=-0.775, \mathrm{p}<0.01)$, but not ward A $(\mathrm{r}=--0.499$, $\mathrm{p}=0.099)$.

\section{Figure 1}

Mean bias and 95\% limits of agreement between estimated energy intakes using weighed plate-wastage and food record charts (FRCs) used in ward $A(n=12)$ and ward $B(n=15)$ in a general hospital

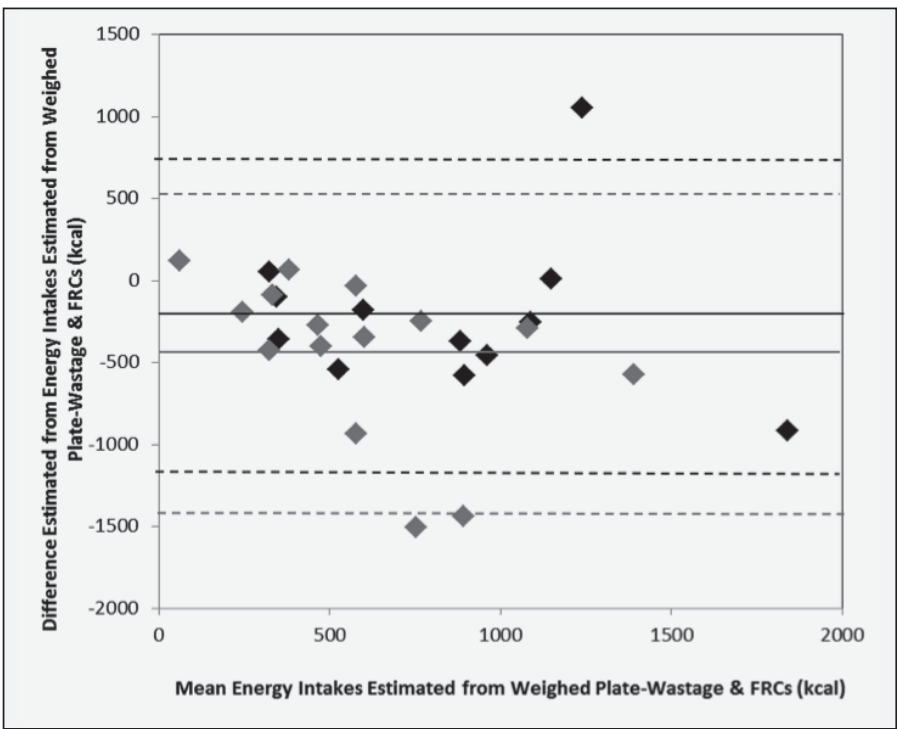

\section{Subjective comparison of completed FRCs}

Subjective comparison of the data obtained from the FRCs and corresponding weighed plate-wastage highlighted discrepancies including: missing data; incorrect food items; additional food items included; and incorrect 'portion eaten' values. One out of the 27 FRCs had food items documented at midday meal only, alongwith no indication or values for 'portion eaten' being recorded. A third of the entire meals consumed across the two wards had not been documented: two out of $12(17 \%)$ of the FRCs from Ward A and seven out of $15(47 \%)$ of the FRCs from Ward B. The main missed documentation of meals at the evening-meal time for both wards: two out of two meals $(100 \%)$ Ward A and six out of seven meals $(86 \%)$ Ward B. On both wards omission of at least one food item from the FRCs was seen in all FRCs on Ward A (12 out of $12(100 \%)$ and 14 out of $15(93 \%)$ of FRCs on Ward B and this was across all eating occasions. Food items frequently not documented were vegetables (six out of seven $(86 \%)$ Ward A; four out of four $(100 \%)$ Ward B), custard (three out of three $(100 \%)$ Ward A; three out of five (60\%) Ward B) and drinks from Ward B (11 out of $15(73 \%)$, particularly during the lunch-time milk round [four out of four (100\%)). Only patients who were observed to have been provided with these food items were included within the analysis.

\section{Figure 2a}

Association between difference between estimated energy (kcal) intakes by plate-wastage and FRC compared with energy intakes estimated from plate-wastage for ward A $(\mathrm{n}=12)$

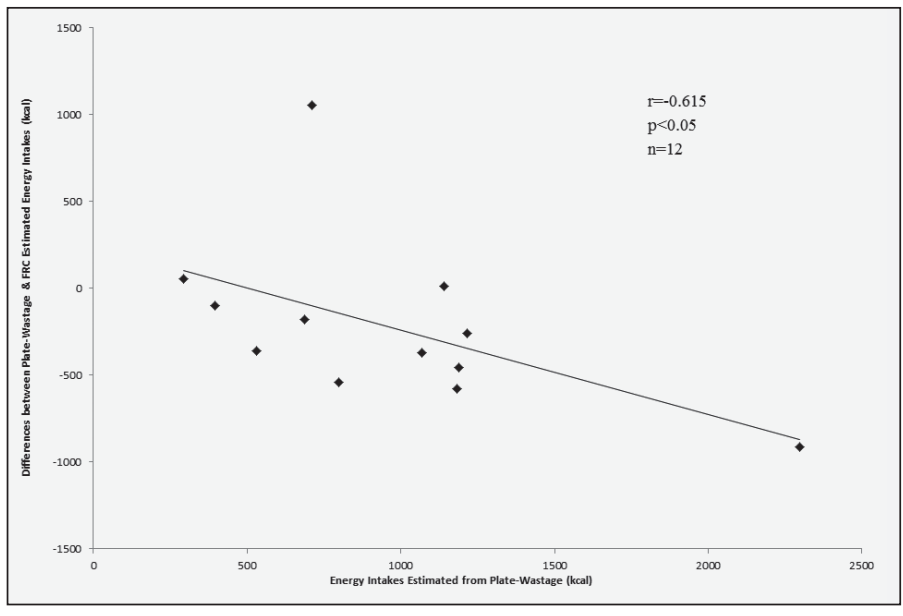

Figure $2 b$

Association between difference between estimated energy (kcal) intakes by plate-wastage and FRC compared with energy intakes estimated from plate-wastage for ward B $(n=15)$

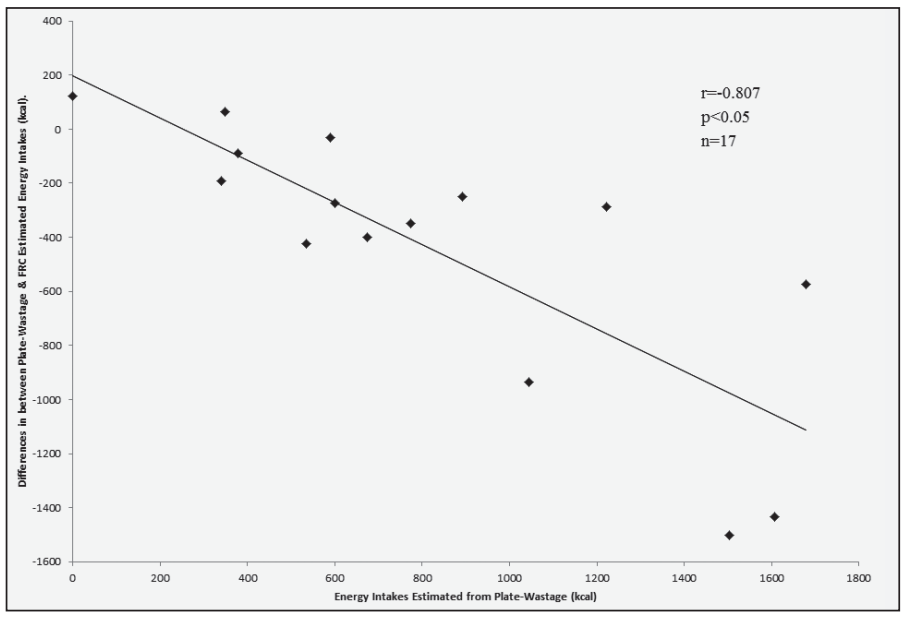

Five out of twelve (42\%) FRCs from Ward A, and two out of $15(13 \%)$ of FRCs from Ward B had additional food items documented on the FRCs that had not been observed. The food items which had been most frequently added were nutritional supplements (three out of five $(60 \%)$ for Ward A; one out of two (50\%) for Ward B).

Two out of twelve (17\%) FRCs (Ward A), and three out of $15(20 \%)$ FRCs (Ward B) had all portion eaten values 
correctly identified and documented. Missed 'portion eaten' values occurred for six out of $12(50 \%)$ FRCs Ward A, and four out of $15(27 \%)$ FRCs Ward B. Of these FRCs, 'portion eaten' values were most frequently missed for lunch-time meals (four out of six $(67 \%)$ ward A; three out of four $(75 \%)$ Ward B), however, this did not occur for any one specific food item.

\section{Discussion}

This pilot study highlights the poor relative validity of FRCs in the estimation of individual patients' food and fluid intakes in the clinical setting. Energy intakes estimated from two semi-quantitative FRCs were on average underestimated by more than $200 \mathrm{kcal}$ on Ward A and $400 \mathrm{kcal}$ on Ward B; this potentially representing approximately 15 to 20 per cent of daily requirements respectively. At the individual level, under estimation of intakes was as high as $1100 \mathrm{kcal}$ on Ward A and 1400kcal on Ward B however the information recorded for some FRCs meant individual patients' intakes were overestimated by up to $500 \mathrm{kcal}$ on Ward A, and $700 \mathrm{kcal}$ on Ward B. These findings raise considerable concern and question the usefulness of the information obtained from FRCs in the clinical setting. Other studies have reported similar findings, although average underestimates were approximately $100 \mathrm{kcal}$, yet as high as $+400 \mathrm{kcal}$ at the individual level with discrepancies largely attributed to inadequate clarity of information documented (18). The accurate monitoring of dietary intakes is fundamental to the identification of nutritionally vulnerable patients (7), to direct, justify and monitor the acceptability of nutritional care plans and dietetic interventions $(10,11)$ and reduce the risk of poor clinical outcomes $(2-4,18)$.

The documentation of food items and quantities consumed were frequently inaccurate or omitted from the FRCs on both wards. Information was frequently missing for the evening meal: FRCs were not collected until after the meal trolley for each ward had returned to the hospital kitchen which suggests that limited entries were made throughout the meal service. Some staff reported that they were not able to document within the FRCs during the time of food or drink consumption and FRCs were completed in retrospect. This may in part explain the inaccuracies and under-reporting identified. Patient recall may be used by staff in order to complete FRCs, however, issues including cognitive impairment and recall bias, can make recall unreliable and misleading (24).

Improvements in completion of FRCs have been observed alongside some fully implemented protected mealtime policies $(25,26)$ However, perceptions amongst nursing staff of the importance of good nutritional care may not be as high a priority as other patient-related care responsibilities (19). Protected mealtimes should enable provision of assistance with eating and drinking to patients who need this, but should also allow for accurate documentation within FRCs and identification of any changes in patients' dietary needs.

Drink and snack items, prepared and delivered to and removed from patients in between meals by domestic staff, often lacked recognition from nursing or CSS and were often not documented, (for example, patients provided with milk frequently had tea or coffee documented in their FRCs). In-between meal snacks and fluids provision is generally not protected like mealtimes, and in many hospitals this service has little involvement from nursing or CSS, especially during the morning hours when complex nursing care duties are primarily undertaken (27). Domestic personnel are not permitted to document within patient records in this hospital thus FRC entries at these times were missed or inaccurately documented.

Despite differences in the scales used to indicate portion consumed on the two FRCs (Ward A using a five point scale and Ward B using a three point scale), inaccuracies in documentation of quantities of foods and fluids was comparable between the wards. This finding suggests potential difficulties for staff in being able to determine quantities of food consumed solely by observation. The use of a Likert scale to record the quantity of food and fluid consumed is a widely used method both within clinical and social care settings (2, $28,29)$ and has been shown to have good agreement with weighed intake methodology (29). Accuracy in visual assessment of the portion eaten is based upon a good awareness of the amount served (28). In the current pilot study, a strong relationship was seen between energy intakes estimated using plate-wastage and the mean difference between energy intakes estimated by the two methods for both wards, suggesting, the more energy consumed, the greater the FRC underestimated energy consumption. Details of food items as well as how much was eaten were both frequently absent. This relationship is unlikely to be due solely to the FRC design. This is more likely attributed to its completion and that the quality of the information documented within FRCs is inconsistent across patients, highlighting the need for training in this area of nutritional care.

The use of pictorial aids that reflect standard portion sizes (12-14), alongside greater training of staff in the visual estimation of portion sizes may assist to achieve a more accurate assessment $(20,21),(29)(28)$. Simplicity and ease of completion are key qualities that need to be balanced against validity: increased complexity to improve validity would be at the expense of compliance, as seen with nutritional screening tools (30)(19).

It is acknowledged that this pilot study is limited by the small sample of FRCs evaluated. However despite the short assessment period, the inaccuracies highlighted raise considerable concern as these results may underestimate what actually happens in practise where FRCs are often kept for three days. Although the food service system standardised the portion size of 
each meal component, it is recognised that there may be some error in portion control and as such, in the weights determined from the mock plated meals to determine estimates of baseline food provision.

\section{Conclusion}

Accurate and consistent completion of FRCs is vital for detecting inadequate intakes among nutritionally vulnerable patients and for their subsequent nutritional care (7). This pilot study highlights two semiquantitative FRCs used within an acute NHS hospital in Scotland have poor validity and significantly underestimate patients' dietary intakes. Staff training on the importance of FRCs and support with development of skills for their completion, including visual estimation of portion sizes served to and consumed by patients are key areas that need addressed. Full implementation of protected mealtimes that recognises the importance of this period for not just assisting with eating and drinking but also monitoring and accurately documenting patients' intakes is required. This in turn should help improve the efficacy of nutritional care provided to patients at risk of malnutrition within hospitals.

Statement of Authorship: LB undertook the study as part of her MSc in Dietetics award at QMU. The study conception was by EB and JJ; LB, JJ and EB designed the study and LB undertook all data collection and analysis. ALL authors were involved in interpretation of the data and the drafting of the paper and have critically reviewed its content and have approved the final version submitted for publication.

Ethical standard: The project was deemed a service evaluation by the South East Scotland Research Ethics Committee

Conflict of interest : None

\section{References}

1. Williams $\mathrm{P}$, Walton $\mathrm{K}$. Plate waste in hospitals and strategies for change. European e-Journal of Clinical Nutrition and Metabolism 2011;6(6):e235-e241.

2. Hiesmayr M, Schindler K, Pernicka E, Schuh C, Schoeniger-Hekele A, Bauer $\mathrm{P}$, et al. Decreased food intake is a risk factor for mortality in hospitalised patients: the NutritionDay survey 2006. Clin Nutr 2009 10;28(5):484-491.

3. Agarwal E, Ferguson M, Banks M, Bauer J, Capra S, Isenring E. Nutritional status and dietary intake of acute care patients: Results from the Nutrition Care Day Survey 2010. Clinical Nutrition 2012 2;31(1):41-47.

4. Agarwal E, Ferguson M, Banks M, Batterham M, Bauer J, Capra S, et al Malnutrition and poor food intake are associated with prolonged hospital stay, frequent readmissions, and greater in-hospital mortality: results from the Nutrition Care Day Survey 2010. Clin Nutr 2013 10;32(5):737-745.

5. NHS Health Improvement Scotland. Food, fluid and nutritional care standards. 2014.

6. NICE. Quality Standard 24: Quality standard for nutrition support in adults. 2012.

7. Council of Europe Resolution. Food and nutritional care in hospitals. How to prevent undernutrition: report and recommendations of the committee of experts on Nutrition, food safety and consumer protection. 2003.

8. Schindler K, Pernicka E, Laviano A, Howard P, Schütz T, Bauer P, et al. How nutritional risk is assessed and managed in European hospitals: a survey of 21,007 patients findings from the 2007-2008 cross-sectional nutritionDay survey. Clin Nutr 2010 10;29(5):552-559.

9. NHS Health Improvement Scotland. Inspecting the care of olde people in acute hospitals 2012a; Available at: http://www. healthcareimprovementscotland.org/our_work/inspecting_and_regulating care/caring_for_older_people.aspx. Accessed March/ 27, 2015.

10. British Dietetic Association. Process and Model for Nutrition and Dietetic Practice 2012.

11. Lacey K, Pritchett E. Nutrition Care Process and Model: ADA adopts road map to quality care and outcomes management. Journal of the American Dietetic Association 2003;103(8):1061-1072.

12. NHS Wales. All Wales Food Record Chart. 2013a; Available at: http: / / www wales.nhs.uk/ sitesplus / documents / 861/Food \%20Record\%20Chart.pdf. Accessed March 30, 2015

13. NHS Wales. Food Record Chart Guide. 2013b; Available at: http://wales. gov.uk/docs/dhss/publications / 110630foodrecordpressen.pdf. Accessed March 30, 2015.

14. NHS Wales. Fluid Volume Guide. 2013c; Available at: http://wales.gov.uk/ docs/dhss/publications/110630fluidVolumepressen.pdf. Accessed March 30, 2015.

15. Buckinghamshire Hospitals NHS Trust. Nutrition Policy. 2013; Available at: http:/ / www.buckshealthcare.nhs.uk/Nutrition/Nutrition\%20Policy.pdf. Accessed March 30, 2015.

16. NHS Liverpool Community Health NHS Trust. Food and Drink Record Chart. Liverpool: Liverpool NHS Primary Care Trust. 2012; Available at: http: / / www.liverpoolcommunityhealth.nhs.uk/ search.htm. Accessed March 30, 2015.

17. Salisbury NHS Foundation Trust. Food Record Chart. Salisbury: Department of Nutrition and Dietetics. No DATE; Available at: http://www.icid. salisbury.nhs.uk/ClinicalManagement/DieteticsAndNutrition/Pages/ FoodRecordChart.aspx. Accessed March 30, 2015.

18. Cartlidge M, Fujiwara T, Richardson RA. Are food record charts useful components of nutritional assessment? Journal of Human Nutrition and Dietetics 2009;22(3):256-256.

19. Raja R, Gibson S, Turner A, et al. Nurses' Views and Practices Regarding Use of Validated Nutrition Screening Tools. Australian Journal of Advanced Nursing 2008;26(1):26-33.

20. Gittelsohn J, Shankar AV, Pokhrel RP, West Jr. KP. Accuracy of estimating food intake by observation. J Am Diet Assoc 1994 11;94(11):1273-1277.

21. Sherwin AJ, Nowson CA, McPhee J, Alexander JL, Wark JD, Flicker L. Nutrient intake at meals in residential care facilities for the aged: validated visual estimation of plate waste. Australian Journal of Nutrition and Dietetics 1998;55:188-193.

22. Cunneen S, Jones, Jacklyn, Davidson, HIM \& Bannerman, Elaine. An investigation of food provision and consumption in a care home setting. British Journal of Community Nursing 2011;16(5):22-28.

23. Martin Bland J, Altman D. Statistical methods for assessing agreement between two methods of clinical measurement. The Lancet 1986 2/8;327(8476):307-310.

24. Tavares MM, Matos L, Amaral TE. Insufficient voluntary intake of nutrients and energy in hospitalised patients. Nutr Hosp 2007;22:584-589.

25. Young AM, Mudge AM, Banks MD, Ross LJ, Daniels LA. Encouraging, assisting and time to EAT : improved nutritional intake for older medical patients receiving Protected Mealtimes and/or additional nursing feeding assistance. . Clinical Nutrition 2013;32(4):543-549.

26. Walton K, Williams P, Tapsell L, Hoyle M, Shen ZW, Gladman L, et al. Observations of mealtimes in hospital aged care rehabilitation wards. Appetite 2013 8/1;67(0):16-21.

27. Williams H, Harris R, Turner-Stokes L. Work sampling: a quantitative analysis of nursing activity in a neuro-rehabilitation setting. J Adv Nurs 2009;65(10):2097-2107.

28. Shatenstein B, Clafeau D, Ferland G. Visual observation is a valid means of assessing dietary consumption among older adults with cognitive deficits in long-term care settings. J American Dietetic Association 2002;102:250-252.

29. Andrews YN, Castellanos VH. Development of a method for estimation of food and fluid intakes by nursing assistants in long-term care facilities: A pilot study. J Am Diet Assoc 2003 7;103(7):873-877.

30. Stratton RJ, Hackston A, Longmore D, Dixon R, Price S, Stroud M, et al Malnutrition in hospital outpatients and inpatients: prevalence, concurrent validity and ease of use of the 'malnutrition universal screening tool' ('MUST') for adults. Br J Nutr 2004;92(05):799-808. 